\title{
Evaluation and assessment of baseline metal contamination in surface sediments from the Bernam River, Malaysia
}

\begin{abstract}
The Bernam River is one of the most important rivers in Malaysia in that it provides water for industries and agriculture located along its banks. The present study was conducted to assess the level of contamination of heavy metals $(\mathrm{Cd}, \mathrm{Ni}, \mathrm{Cr}, \mathrm{Sn}$, and $\mathrm{Fe})$ in surface sediments in the Bernam River. Nine surface sediment samples were collected from the lower, middle, and upper courses of the river. The results indicated that the concentrations of the metals decreased in the order of $\mathrm{Sn}>\mathrm{Cr}>\mathrm{Ni}>\mathrm{Fe}>\mathrm{Cd}\left(56.35,14.90,5.3,4.6\right.$, and $0.62 \mu \mathrm{g} / \mathrm{g}^{1}$ dry weight). Bernam River sediments have moderate to severe enrichment for Sn, moderate for $\mathrm{Cd}$, and no enrichment for $\mathrm{Cr}, \mathrm{Ni}$, and $\mathrm{Fe}$. The contamination factor (CF) results demonstrated that $\mathrm{Cd}$ and $\mathrm{Sn}$ are responsible for the high contamination. The pollution load index (PLI), for all the sampling sites, suggests that the sampling stations were generally unpolluted with the exception of the Bagan Tepi Sungai, Sabak Bernam, and Tanjom Malim stations. Multivariate techniques including Pearson's correlation and hierarchical cluster analysis were used to apportion the various sources of the metals. The results suggested that the sediment samples collected from the upper course of the river had lower metal concentrations, while sediments in the middle and lower courses of the river had higher metal concentrations. Therefore, our results can be useful as a baseline data for government bodies to adopt corrective measure on the issues related to heavy metal pollution in the Bernam River in the future.
\end{abstract}

Keyword: Heavy metals; Geoaccumulation index; Enrichment factor; Contamination factor; Cluster analysis; Sediment quality guideline; Bernam River 